\title{
Gait Asymmetry During 400- to 1000-m High-Intensity Track Running in Relation to Injury History
}

\author{
Rahel Gilgen-Ammann, Wolfgang Taube, and Thomas Wyss
}

\begin{abstract}
Purpose: To quantify gait asymmetry in well-trained runners with and without previous injuries during interval training sessions incorporating different distances. Methods: Twelve well-trained runners participated in 8 high-intensity interval-training sessions on a synthetic track over a 4 -wk period. The training consisted of $10 \times 400,8 \times 600,7 \times 800$, and $6 \times 1000$-m running. Using an inertial measurement unit, the ground-contact time (GCT) of every step was recorded. To determine gait asymmetry, the GCTs between the left and right foot were compared. Results: Overall, gait asymmetry was $3.3 \% \pm 1.4 \%$, and over the course of a training session, the gait asymmetry did not change $\left(F_{1,33}=1.673, P=.205\right)$. The gait asymmetry of the athletes with a previous history of injury was significantly greater than that of the athletes without a previous injury. However, this injuryrelated enlarged asymmetry was detectable only at short $(400 \mathrm{~m})$, but not at longer, distances $(600-1000 \mathrm{~m})$. Conclusion: The gait asymmetry of well-trained athletes differed, depending on their history of injury and the running distance. To detect gait asymmetries, high-intensity runs over relatively short distances are recommended.
\end{abstract}

Keywords: imbalance, field condition, fatigue, inertial measurement unit, high performance

Athletes and coaches assume that gait asymmetry affects athletic performance, as 1 of the lower limbs is exposed to more stress than the other. ${ }^{1,2}$ Gait asymmetry can be the primary cause of an injury and it can be responsible for an injury. ${ }^{1,3,4}$ Previously, gait asymmetries ranging from $3 \%$ for knee angle at touchdown to $54 \%$ for hip-angle velocity were reported in female runners, 5,6 suggesting that a single threshold level of normal to problematic gait asymmetry does not exist and that there are wide variations in gait mechanics and asymmetries. ${ }^{1,18}$ Also, gait asymmetry may not be evident at the beginning of a race but may emerge with fatigue. Regarding injury history, some earlier studies of athletes with and without a previous injury found no differences in gait asymmetry. $1,7,8$ However, all the subjects in the aforementioned studies were either novice runners, ${ }^{7}$ the assessments took place in a laboratory setting (on a treadmill) at submaximal speeds only, ${ }^{1,7-9}$ and only 1 trial $^{10}$ or a few gait cycles ${ }^{9}$ were analyzed. Consequently, it is unclear whether these results are congruent with real practice during training or competition on realistic floor conditions. For instance, a previous study provided evidence that gait asymmetry is reduced on a treadmill. ${ }^{11}$ Hence, to better understand the occurrence of gait asymmetry, data from well-trained runners over entire runs over various distances, at high speeds, and at high intensities need to be obtained in field measurements.

The purpose of this study therefore was threefold: to quantify gait asymmetry in healthy well-trained runners during high-intensity track runs of different lengths and speeds (400-1000 m), to evaluate the effect of an injury in the previous 24 months on gait asymmetry when compared with noninjured runners, and to examine whether gait asymmetry changed within the course of exhausting training

Gilgen-Ammann and Wyss are with the Swiss Federal Inst of Sport Magglingen SFISM, Magglingen, Switzerland. Taube is with the Dept of Medicine, Movement and Sport Science, University of Fribourg, Fribourg, Switzerland. Address author correspondence to Rahel Gilgen-Ammann at rahel.ammann@baspo.admin.ch. sessions. To realize these aims, the ground-contact times (GCTs) of right and left foot were chosen to assess gait asymmetry. Despite a variety of other parameters that were already shown to characterize gait asymmetry, such as knee/foot angle at touchdown or peak lateral ground-reaction force, ${ }^{1,5}$ GCT was defined as it can easily be obtained during field measurements while the athletes are freely moving.

\section{Methods}

\section{Subjects}

Seven male and 5 female participants $(35.7 \pm 10.1 \mathrm{y}, 68.3 \pm 10.3 \mathrm{~kg}$, $1.74 \pm 0.09 \mathrm{~m}$ ) were recruited for this pilot study. The participants were well-trained middle- to long-distance athletes, with $11.9 \pm 7.8$ years of running experience and $410 \pm 205$ minutes of weekly training practice. Informed consent was obtained from all the subjects after familiarization with the procedure. The research procedure was approved by the institutional review board of the Federal Office of Sport and was in accordance with the Declaration of Helsinki.

\section{Methodology}

Data were obtained during interval training sessions on a synthetic track, while all the participants wore normal running shoes. As the running speed can affect gait asymmetry, data were obtained from 8 training sessions differing in length: $10 \times 400 \mathrm{~m}$ (90-s rest), $8 \times$ $600 \mathrm{~m}$ (100-s rest), $7 \times 800 \mathrm{~m}$ (120-s rest), and $6 \times 1000 \mathrm{~m}(150-\mathrm{s}$ rest). Runs were performed at subjective intensities of $80 \%$ to $100 \%$ and Borg values 6 to 20 were assessed after each trial. ${ }^{12}$ The measurements took place over a period of 4 weeks, with 2 interval sessions per week; hence, every training content was accomplished twice over the course of this study.

The GCTs of right and left leg were chosen to assess gait asymmetry. Although running depends on a variety of parameters, the GCT is the only moment during running to generate propulsive 
force. The ability to symmetrically produce and transmit high amounts of muscle force to the ground over a short period of time is therefore a major determinant of performance in running. ${ }^{13-15}$ Moreover, it was shown that $90 \%$ to $96 \%$ of the variance in leg stiffness can be explained by the GCT. ${ }^{16}$ During the ground contact, different kinematic and kinetic parameters are interacting and it is assumed that symmetric activation is important. ${ }^{1-4}$ In a study with Kenyan distance runners, the only significant difference between left and right leg was detected when analyzing the GCTs. ${ }^{9}$ Despite the significance, these authors quoted that it is debatable whether the detected gait asymmetry in GCTs is related to injury. Subsequently, to elaborate on that topic in free-living conditions, differences in GCTs of both feet were assessed in subjects with and without previous injuries.

An inertial measurement unit (Axiamote; Axiamo, Biel, Switzerland) was used to assess the GCTs of every step. The Axiamote is a small $(3.8 \times 3.7 \times 0.8 \mathrm{~cm})$, lightweight $(13-\mathrm{g})$ device, which records accelerometer data with a full-scale range of $\pm 16 \mathrm{~g}$ and a sampling rate of $1000 \mathrm{~Hz}$. A previous study demonstrated the validity and reliability of the device in the measurement of GCTs. ${ }^{17}$ This method is feasible in field conditions in entire groups to gain insight into gait asymmetries, unlike other methods that rely on, for example, the braking impulse or joint angles, which are much more difficult to assess.

Injury histories during the previous 24 months were recorded using an online questionnaire. The inclusion criteria for the previously injured group $(n=6,2$ female) included an injury of 1 or multiple injuries of the lower extremities in the past 24 months, which caused the athlete to miss at least one week of training. Three subjects reported ankle sprains, 2 subjects Achilles tendinitis, and 1 participant, shin tendinitis. All athletes included in this study were fully recovered and injury free. The noninjured group $(n=6,3$ female) consisted of runners who had not experienced any injuries in the previous 24 months.

\section{Statistical Analysis}

Gait asymmetry was calculated as in the following equation ${ }^{1,10,18,19}$ :

$$
\frac{\mid \text { GCT right }- \text { GCT left } \mid}{0.5 \times(\text { GCT right }+ \text { GCT left })} \times 100=\text { gait asymmetry }(\%)
$$

To examine whether gait asymmetry differed, depending on the running distance and injury group, a $2 \times 4$ repeated-measures ANOVA followed by Bonferroni-corrected post hoc analyses were performed. Cohen $d$ effect size was calculated to determine the magnitude of the between-groups differences. ${ }^{20}$ To evaluate changes over the course of the interval sessions, the first 2 and last 2 runs of each interval session were compared. For this purpose, a $2 \times 2$ repeated-measures ANOVA was applied to investigate changes by time (ie, the first 2 and last 2 runs of each interval session) and group (ie, athletes with and without an injury history). The statistical analyses were executed with SPSS 23.0 (SPSS, Inc, Chicago, IL, USA), and significance was set at $P \leq .05$.

\section{Results}

In total, 641 interval runs were performed, with an average speed of $4.8 \mathrm{~m} / \mathrm{s}$ (range $3.9-5.9 \mathrm{~m} / \mathrm{s}$ ) and GCTs of 197.7 milliseconds (range 164.7-242.3 milliseconds). Overall, gait asymmetry was $3.3 \% \pm$ $1.4 \%$ (range $1.5-7.9 \%$; Table 1 ). The $2 \times 4$ repeated-measures ANOVA revealed significant group $\left(F_{1,9}=4.673, P=.026\right)$, distance $\left(F_{3,27}=16.763, P<.001\right)$, and interaction effects $\left(F_{3,27}=5.083\right.$, $P=.006)$. Shorter running distances were correlated with faster speeds and shorter GCTs, and led to enlarged gait asymmetry ( $r$ $=-.175, P<.001)$. No changes in gait asymmetry over the course of an interval training session $\left(F_{1,33}=1.673, P=.205\right)$ or time $\times$ group effects $\left(F_{1,33}=2.816, P=.103\right)$ were detected. There were no significant gait asymmetries when comparing GCTs of dominant and nondominant leg $(P=.098)$ in the noninjured group, whereas in the previously injured group the GCTs of the injured side were significantly longer than the GCTs of the noninjured side $(P<$ .001). The reported Borg values after the end of each session were on average 17.9 (range 16-20), indicating very hard to extremely hard exertion. Buildup of fatigue was therefore expected.

\section{Discussion}

Well-trained male and female runners showed, on average, $3.3 \% \pm$ $1.4 \%$ gait asymmetry during high-intensity interval runs over different distances. This finding confirms former reported gait asymmetries of $2.6 \%$ to $3.6 \%$ in distance runners. ${ }^{8-10}$ However, in some of these earlier studies, the data were based on treadmill running, ${ }^{8,9}$ which was shown to decrease gait asymmetry. ${ }^{11}$

To some extent, gait asymmetry appears to be natural, due to acquired individual running patterns and/or differences in leg length. 4,21,22 A previous study reported that the GCTs of the left foot were significantly longer than those of the right foot while running around the bend of a synthetic track. ${ }^{10}$ In the current study, a previous injury was associated with gait asymmetry, with the athletes who had a previous injury having significantly enlarged gait asymmetry compared with those without a history of injury. Hence, our field measurements are in contrast to the findings of earlier studies of

Table 1 Gait Asymmetry Depending on Running Distance and Injury History

\begin{tabular}{|c|c|c|c|c|c|c|c|}
\hline \multirow[b]{2}{*}{ Distance (m) } & \multirow[b]{2}{*}{ Speed $(\mathrm{m} / \mathrm{s})$} & \multirow[b]{2}{*}{ GCT (ms) } & \multirow[b]{2}{*}{ Borg (6-20) } & \multicolumn{4}{|c|}{ Gait Asymmetry (\%) } \\
\hline & & & & Overall, $\mathrm{n}=12$ & Previous injury, $n=6$ & No injury, $n=6$ & ES \\
\hline Overall & $4.8 \pm 0.4$ & $197.7 \pm 14.7$ & $17.9 \pm 1.1$ & $3.3 \pm 1.4$ & $3.6 \pm 1.6$ & $3.0 \pm 1.2 *$ & 0.43 \\
\hline 400 & $5.0 \pm 0.3$ & $188.9 \pm 11.6$ & $18.0 \pm 1.2$ & $3.7 \pm 1.5$ & $4.1 \pm 1.6$ & $3.2 \pm 1.3 *$ & 0.62 \\
\hline 600 & $4.8 \pm 0.4$ & $196.8 \pm 12.1$ & $17.9 \pm 0.9$ & $3.3 \pm 1.3$ & $3.5 \pm 1.3$ & $3.1 \pm 1.2$ & 0.32 \\
\hline 800 & $4.6 \pm 0.4$ & $205.4 \pm 14.1$ & $17.9 \pm 1.3$ & $2.7 \pm 0.9$ & $2.6 \pm 0.8$ & $2.8 \pm 0.9$ & 0.24 \\
\hline 1000 & $4.5 \pm 0.3$ & $208.5 \pm 11.5$ & $17.8 \pm 1.0$ & $2.7 \pm 1.2$ & $2.9 \pm 1.4$ & $2.7 \pm 1.0$ & 0.16 \\
\hline
\end{tabular}

Abbreviations: GCT, ground-contact time; ms, milliseconds; ES, Cohen $d$ effect size.

$* P<.05$ between groups with and without a previous history of injury. 
previously injured and noninjured subjects that found no difference in gait asymmetry measured in laboratory settings. ${ }^{1,7,8}$ The discord between the studies might be explained by investigating different biomechanical parameters ${ }^{5,6}$ and/or by the finding that gait asymmetry was significantly reduced when subjects with knee osteoarthritis switched from overground to treadmill running. ${ }^{11}$ Hence, treadmill running might mask injury-related gait asymmetries. Furthermore, gait asymmetry seems to be more apparent during individual faster speeds, as gait asymmetry increased during the shorter interval runs in the current study (Table 1). It may be hypothesized that greater running speeds require not only higher forces but also more sophisticated running patterns, as the degree of freedom of the body must be coordinated in less time. ${ }^{23}$ In the current study, the generally enlarged gait asymmetry at higher speeds was even more prevalent in the group with a previous injury, most likely due to muscular or neuromuscular deficits in the previously injured leg. In line with this assumption, all subjects displayed longer GCTs of the previously injured leg compared with the healthy leg, indicating a lower momentum to generate propulsive force. Consequently, as injury-related differences in gait asymmetry seem to be more detectable during strenuous activity, gait asymmetry assessments should be made during high-intensity exercise.

In contrast, the emergence of fatigue within training sessions did not exacerbate gait asymmetry in any injury group. A recent study reported similar results, finding no changes in gait asymmetry over the course of a $5-\mathrm{km}$ time trial in elite orienteers. ${ }^{10}$ However, other studies showed significant changes between start and end phases of time trials in step length, step frequency, GCT, or total stride duration. ${ }^{24,25}$ Consequently, neither changes in gait asymmetry over a course of a time trial nor changes in gait asymmetry over the course of a complete high-intensity interval training session seem to be indicators of emerging fatigue in elite or well-trained athletes, respectively.

\section{Practical Applications}

Based on the findings of the current study, gait asymmetry seems to differ according to the running distance and consequently the running speed. This gait asymmetry was even more prevalent among the athletes with a previous history of injury. To ensure that gait asymmetry is not masked, data should be collected during overground runs at high speeds. Moreover, for the targeted development of athletes, individual analyses and long-term data are required and recommended. Therefore, baseline "gait asymmetry values" should be obtained in the healthy state at individual fast running speeds. Based on these values, the injury-related increase in gait asymmetry can be quantified and counteracted. Such information could be of importance for athletes' recovery after an injury or young athletes who are still developing their running style. ${ }^{26-28}$ Future studies with enlarged sample size and controlled/prospective injury assessment could investigate gait asymmetry in the field in different settings to determine the possible influences of training loads or injuries on running patterns.

\section{Conclusion}

Gait asymmetry between the GCT of the left and right foot in welltrained athletes during 400- to 1000-m high-intensity interval runs was, on average, $3.3 \% \pm 1.4 \%$, and gait asymmetry was greater in runners with than in those without a previous injury. Furthermore, gait asymmetry increased at shorter running distances, suggesting that injury-related differences may manifest themselves at this point. In contrast, over the course of highly demanding training sessions, emerging fatigue was not associated with increases in gait asymmetry.

\section{Acknowledgment}

The authors thank the participants for their effort and compliance. We do have no conflicts of interest to declare and the results of the current study do not constitute endorsement of the product by the authors or the journal.

\section{References}

1. Zifchock RA, Davis I, Hamill J. Kinetic asymmetry in female runners with and without retrospective tibial stress fractures. J Biomech. 2006;39(15):2792-2797. PubMed doi:10.1016/j. jbiomech.2005.10.003

2. Ciacci S, Di Michele R, Fantozzi S, Merni F. Assessment of kinematic asymmetry for reduction of hamstring injury risk. Int J Athl Ther Train. 2013;18(6):18-23. doi:10.1123/ijatt.18.6.18

3. Croisier JL, Forthomme B, Namurois MH, Vanderthommen M, Crielaard JM. Hamstring muscle strain recurrence and strength performance disorders. Am J Sports Med. 2002;30(2):199-203. PubMed

4. Perttunen JR, Anttila E, Sodergard J, Merikanto J, Komi PV. Gait asymmetry in patients with limb length discrepancy. Scand J Med Sci Sports. 2004;14(1):49-56. PubMed doi:10.1111/j.1600-0838.2003.00307.x

5. Karamanidis K, Arampatzis A, Bruggemann GP. Symmetry and reproducibility of kinematic parameters during various running techniques. Med Sci Sports Exerc. 2003;35(6):1009-1016. PubMed doi:10.1249/01.MSS.0000069337.49567.F0

6. Williams KR, Cavanagh PR, Ziff JL. Biomechanical studies of elite female distance runners. Int J Sports Med. 1987;8(Suppl 2):107-118. PubMed doi:10.1055/s-2008-1025715

7. Bredeweg SW, Buist I, Kluitenberg B. Differences in kinetic asymmetry between injured and noninjured novice runners: a prospective cohort study. Gait Posture. 2013;38(4):847-852. PubMed doi:10.1016/j.gaitpost.2013.04.014

8. Brughelli M, Cronin J, Mendiguchia J, Kinsella D, Nosaka K. Contralateral leg deficits in kinetic and kinematic variables during running in Australian Rules football players with previous hamstring injuries. J Strength Cond Res. 2010;24(9):2539-2544. PubMed doi:10.1519/ JSC.0b013e3181b603ef

9. Kong PW, de Heer H. Anthropometric, gait and strength characteristics of Kenyan distance runners. J Sports Sci Med. 2008;7(4):499-504. PubMed

10. Ammann R, Taube W, Wyss T. Gait asymmetry during a 5-km time trial in elite runners: a descriptive study. In: Cabri J, PezaratCorreia P, Barreiros J, eds. Sports Science Research and Technology Support. 2016; Cham, Switzerland: Springer International. doi:10.1007/978-3-319-52770-3_2

11. Robadey J, Schween R, Gehring D, Staudenmann D. Change of symmetry between overground and treadmill running with a chronic knee injury. Paper presented at: 19th Congress of the European Society of Biomechanics, Patras, Greece, August 25-28, 2013.

12. Borg G. Perceived exertion as an indicator of somatic stress. Scand $J$ Rehabil Med. 1970;2(2):92-98. PubMed

13. Meyers RW, Oliver JL, Hughes MG, Lloyd RS, Cronin JB. The influence of maturation on sprint performance in boys over a 21-month period. Med Sci Sports Exerc. 2016;48(12):2555-2562. PubMed doi:10.1249/MSS.0000000000001049

14. Paavolainen L, Hakkinen K, Hamalainen I, Nummela A, Rusko H. Explosive-strength training improves 5-km running time by improving 
running economy and muscle power. J Appl Physiol. 1999;86(5):1527_ 1533. PubMed

15. Weyand PG, Sternlight DB, Bellizzi MJ, Wright S. Faster top running speeds are achieved with greater ground forces not more rapid leg movements. J Appl Physiol. 2000;89(5):1991-1999. PubMed

16. Morin JB, Dalleau G, Kyrolainen H, Jeannin T, Belli A. A simple method for measuring stiffness during running. J Appl Biomech. 2005;21(2):167-180. PubMed doi:10.1123/jab.21.2.167

17. Ammann R, Taube W, Wyss T. Accuracy of PARTwear inertial sensor and Optojump optical measurement system for measuring ground contact time during running. J Strength Cond Res. 2016;30(7):2057-2063. PubMed

18. Robinson RO, Herzog W, Nigg BM. Use of force platform variables to quantify the effects of chiropractic manipulation on gait symmetry. J Manipulative Physiol Ther. 1987;10(4):172-176. PubMed

19. Herzog W, Nigg BM, Read LJ, Olsson E. Asymmetries in ground reaction force patterns in normal human gait. Med Sci Sports Exerc. 1989;21(1):110-114. PubMed doi:10.1249/ 00005768-198902000-00020

20. Cohen J. Statistical Power Analysis for the Behavioral Sciences. 2nd ed. Hillsdale, NJ: L. Erlbaum; 1988.

21. Cavanagh PR, Williams KR. The effect of stride length variation on oxygen uptake during distance running. Med Sci Sports Exerc. 1982;14(1):30-35. PubMed doi:10.1249/00005768-198201000-00006
22. Gurney B. Leg length discrepancy. Gait Posture. 2002;15(2):195-206. PubMed doi:10.1016/S0966-6362(01)00148-5

23. Li Y, Wang W, Crompton RH, Gunther MM. Free vertical moments and transverse forces in human walking and their role in relation to arm-swing. J Exp Biol. 2001;204(Pt 1):47-58. PubMed

24. Girard O, Millet GP, Slawinski J, Racinais S, Micallef JP. Changes in running mechanics and spring-mass behaviour during a $5-\mathrm{km}$ time trial. Int J Sports Med. 2013;34(9):832-840. PubMed doi:10.1055/s-0032-1329958

25. Nummela AT, Heath KA, Paavolainen LM, et al. Fatigue during a 5-km running time trial. Int J Sports Med. 2008;29(9):738-745. PubMed doi:10.1055/s-2007-989404

26. Halson SL. Monitoring training load to understand fatigue in athletes. Sports Med. 2014;44(Suppl 2):S139-S147. PubMed doi:10.1007/ s40279-014-0253-z

27. Hayes P, Caplan N. Foot strike patterns and ground contact times during high-calibre middle-distance races. J Sports Sci. 2012;30(12):12751283. PubMed doi:10.1080/02640414.2012.707326

28. Leskinen A, Hakkinen K, Virmavirta M, Isolehto J, Kyrolainen $\mathrm{H}$. Comparison of running kinematics between elite and nationalstandard 1500-m runners. Sports Biomech. 2009;8(1):1-9. PubMed doi:10.1080/14763140802632382 